four hundred brass stencils, apparently used by Franklin in the study and designing of type, as well as inventories of fonts cast at Passy and of type and other printing materials purchased from the leading English, French and possibly Dutch type-founders. Other articles in this number include Prof. G. Chinard's study of Franklin as negotiator, December 1777, Prof. P. A. W. Wallace's appreciation of H. E. Muhlenberg's work as botanist, Prof. T. D. Cope's note "Collecting Some Material about Charles Mason and Jeremiah Dixon", the astronomers and geodetic surveyors, and Prof. I. J. Cox's account of the Freeman Red River Expedition of 1806.

\section{Establishment of Hardwoods in Britain}

MANY will welcome the small Forestry Commission pamphlet No. 2 of the Forest Operations Series (who invents these cumbersome titles?) on the "Establishment of Hardwoods" (London: H.M. Stationery Office. $9 d$. net). The small area of 35,000 acres only was afforested or replanted in Britain with various hardwoods during the first twenty-five years of the Forestry Commission. A bulletin recording the information so far gathered on the subject of sowing and planting to form the new plantations was in the press just before the outbreak of war, but was destroyed during the bombing of London. The present one has been prepared from a report of $\mathrm{Mr}$. A. H. Popert, acting conservator in the south-west of England, as a result of a tour of the Commission's hardwood plantations. It is perfectly well known that the raising and tending of young hardwood crops, save in exceptionally favourable circumstances of habitat, are more difficult and call for more experience than is required for conifers. The bulletin gives notes on the chief timber species-oak, beech, ash, sycamore, sweet chestnut, birch and alder. It also deals with the treatment of coppice woods and devastated woodlands ; on these latter subjects, some who have lived with and studied coppice areas may differ from the views contained in the paper. As a result of war-time and present-day fellings of the fine hardwoods, it is noted that the "Establishment of broadleaved trees is likely to assume increasing importance in British Forestry".

\section{"Not poppy, nor mandragora ...."}

"An Index of Modern Remedies", by William Mair, has, since it was first published in 1941 , been useful to the medical and pharmaceutical professions, to whom alone it is issued. The appearance of a new edition (Fourth Series, 1948. Scottish Chemist, 240 Albert Drive, Pollokshields, Glasgow, S.1 ; and from Messrs. H. K. Lewis and Co., Ltd., 136 Gower Street, London. 3s.) will therefore be welcomed. This new edition contains, as well as a few recently coined names of remedies, a valuable article on the 1948 edition of the British Pharmacopœia, with lists of the 250 new admissions to this publication and of the omissions from it. There is also a useful list of costly and essential drugs now exempted from the purchase tax. As Mr. Mair rightly says in his introductory note, no physician or pharmacist can nowadays be familiar with the names, composition and action of all the pharmaceutical preparations on the market, and he has set out to give this information in a handy and well-indexed form. He also gives, by means of a key, the names and addresses of manu. facturing chemists and the preparations which they make. Using this book, one realizes how many names some drugs nowadays have, the changes these names have undergone and how different they may be in different countries. Pentothal, for example, is now thiopentone soluble B.P. and U.S.P., and aminacrine hydrochloride B.P. used to be, and no doubt still is in some quarters, acramine, monacrin or acramine yellow. The maze of names given to the antimalarial drugs and to the sulphonamides and their derivatives are here sorted out, and a short supplement lists special injection solutions for parenteral therapy. More than half the book is devoted to a classification of various remedies according to their mode of action. In this section the statement that phenothiazine is an anthelmintic of low toxicity needs modification. As Prof. J. H. Gaddum says in his foreword, this book is a valuable guide and provides information not easily obtained elsewhere, even in more expensive books.

\section{Pfund Issue of the Journal of the Optical Society of America}

The October 1947 issue of the Journal of the Optical Society of America is the largest issue of the journal ever to be published and was specially called the "Pfund Issue". It consists of articles written by Prof. A. H. Pfund's former students and colleagues and is a tribute to him on his retirement from active teaching at the Johns Hopkins University. An advance copy of this issue, together with a 'scrapbook' containing the letters which accompanied the manuscripts of the articles when they were submitted for publication, was presented to Prof. Pfund at the dinner held during the thirty-second annual meeting of the Society in October last. A photograph of Prof. Pfund is on the opening page, and the first of the twenty-three articles in the issue is by Prof. R. W. Wood, who writes on "The Use of Echelette Gratings in High Orders". Two of the articles are actually by Prof. Pfund himself and co-workers, but he was unaware that his colleagues had submitted the papers for a special issue of the Journal. They deal with selective infra-red gas analysers and with optical scattering by dielectric powders. The other articles include: a historical note on the rate of a moving clock by H. E. Ives; a spark light-source of short duration by J. W. Beams and others; an optical study of acoustic fields near diffraction edges by J. C. Hubbard and others; and practical methods of making and using multilayer filters by Mary Banning.

\section{Hot-wire Vacuum Switches}

Sunvic Controls, Lrd., 10 Essex Street, Strand, London, W.C.2, manufacturers of vacuum switches, temperature control and associated equipment, have recently issued a 16-page illustrated pamphlet describing their hot-wire vacuum switches. The Sunvic hot-wire vacuum switch is contained within an evacuated glass tube not much larger than an ordinary radio valve, and is a non-arcing electric relay, the operation of which depends on the fact that when an electric current is interrupted by the separation of two surfaces in a vacuum no arc is formed. The movement necessary to close or open the switch is quite small and is provided by the thermal expansion of a special steel wire through which a control current of some $25-60 \mathrm{~m}$.amp. is passed. The switch contacts are tungsten and are normally held apart against a compressed spring, which is released by the expansion of the hot wire. The operating characteristics of many different forms of hot-wire vacuum switches with various time delays, 